|| Print ISSN: 2589-7837 || Online ISSN: 2581-3935 ||

International Journal of Medical Science and Diagnosis Research (IJMSDR)

Available Online at www.ijmsdr.com

NLM (National Library of Medicine ID: 101738824)

Original Research Article

Volume 5, Issue 10; October:2021; Page No. 42-50

\title{
Prevalence of Antenatal Depression in a Teaching Hospital South/South Nigeria.
}

\author{
Enyidah Nonyenim Solomon ${ }^{\mathbf{1}}$, Nonye-Enyidah Esther Ijeoma ${ }^{2}$ \\ ${ }^{1}$ Department of Medicine, Faculty of Clinical Sciences, College of Health Sciences, Rivers State \\ University, Port Harcourt, Rivers State Nigeria. \\ ${ }^{2}$ Department of Obstetrics and Gynaecology, Rivers State University Teaching Hospital, Port \\ Harcourt, Rivers State Nigeria.
}

\section{Conflicts of Interest: Nil}

Corresponding author: Enyidah Nonyenim Solomon

DOI: https://doi.org/10.32553/ijmsdr.v5i10.868

\begin{abstract}
:
Background: Over 30 million people living in Africa suffer from depression which also contributes to global burden of diseases with a steady rise in prevalence, affecting all groups, including pregnant women. Factors which account for the psychological effects of pregnancy on mothers include; maternal age, planned pregnancy, previous experiences, spouse support, and partner violence. These risk factors may lead to antenatal depression which endangers the mother and the pregnancy. To safeguard mothers from depression during pregnancy, these factors need to be determined.

Objective: To determine the prevalence, risk factors and predictors of antenatal depression.

Methods: Pregnant women attending antenatal care, who met the study inclusion criteria were interviewed and screened for depression using the risk factor and socio-demographic questionnaire and Edinburgh Postnatal Depression Scale (EPDS). Data obtained was fed into the statistical package for social sciences (SPSS) version 23.0 and cross-tabulation of the relevant variables obtained using chisquared and t-test. $P$ values $<0.05$ were statistically significant.

Results: Of 500 respondents, 158 (31.6\%) had depression. Risk factors of cohabiting with spouse, lack of financial support from spouse, fight with spouse, threat to life, history of still birth and child health challenges were determined, four of which turned out to be predictors of antenatal depression (AD).

Conclusion: The high prevalence of $31.6 \%$ of antenatal depression calls for a review of obstetrics practice to include screening and diagnosis for antenatal depression.
\end{abstract}

Keywords: Antenatal depression, socio-demographic factors, EPDS, Obstetrics risk factors, social support, predictors.

\section{Introduction:}

Depression is one of the mood disorders occurring either as unipolar or bi-polar. It mainly presents with decreased or loss of interest or pleasure in self and most activities. It may present with disturbances and alterations in weight, sleep, energy levels, appetite, cognitive abilities and self esteem [1]. More than 322 million people are living with depression, with about 30 million living in Africa [2]. Depression is one of the top five contributors to global disease burden with a global steady rise in prevalence [3]. This rise affects virtually all groups including pregnant women. 
Pregnancy is typically depicted as a joyful, ecstatic time for expectant mothers. It is a well-known fact that the surge of hormones and changes a woman's body goes through can trigger all sorts of psychological changes. Such changes depend on several factors including whether the pregnancy was planned, whether the baby was wanted, the relationship with spouse, age of mother, previous experiences and expectations. Many women report that being pregnant is a creative act gratifying a fundamental need and self-actualization, while others may view pregnancy negatively for several reasons which may include childbirth challenges and inadequate mothering potentials. [4]

Depression during prenatal period is identified as a risk factor for adverse obstetrics and birth outcome like foetal growth retardation, low apgar score, preterm birth, low birth weight and still birth. Reports from low and middle income countries showed that pregnant women with depression were more likely to suffer from obstetrics complications such as pre-eclampsia, uterine irritability and pregnancy induced hypertension.[5] Women in developing countries such as Nigeria, are more exposed to the risk factors for the development of antenatal depression such as young age of mothers, early marriage, low level of education, exposure to domestic violence, unplanned pregnancy, lack of social support and low economic status.[6]

Epidemiological study across Africa in 2020 showed that risk factors such as financial difficulties, poor support from relations, poor obstetric care and history were additional risk factors common in the continent. [7] Okechukwu et. al (2016) discussed the effect of alcohol use and previous caesarean section on pregnant women. A few more researches have been done in Nigeria on antenatal depression, one study focussed on antenatal depression in the third trimester [8]. To date no known research on antenatal depression has been reported from this part of Nigeria. This study is therefore designed to add to the growing knowledge on antenatal depression and to highlight on prevalent predictors of antenatal depression in this part of the country.

\section{Methods:}

\section{Study setting and population:}

The study was conducted in the department of obstetrics and gynaecology (O\&G) of the Rivers State University Teaching Hospital in Port Harcourt, Nigeria. The hospital is one of the few major referral hospitals providing services for over five million residents within the state. It allows unrestricted access to all inhabitants and the O\&G department provides services to all women requiring their services. The antenatal unit of the hospital registers all pregnant women desiring antenatal care, irrespective of their source of referral. The study was a cross sectional questionnaire one conducted from $1^{\text {st }}$ January, 2020 to $1^{\text {st }}$ February, 2020 and included all pregnant women who registered for antenatal care and follow-up review, who were in good mental and physical health and who had a minimum of primary education. All pregnant women who met the inclusion criteria were properly educated about the study, and were requested to sign a consent form. Only those who consented to the study were allowed to participate in the study.

\section{Data collection:}

Data was obtained by means of personal interview with the respondents, a respondent information sheet that explained the purpose of the study was given to all the respondents and they were assured of privacy and confidentiality of the data. Each respondent was made to respond to two questionnaires, one was a study designed sociodemographic and risk factor questionnaire and the second was the EPDS. The study designed questionnaire has three sections, the first section contained socio-demographic information of age, level of education, employment and marital status. The second section contained financial and spouse information while the third section accessed obstetrics and family history. Each respondent went through the questionnaires and responded appropriately.

\section{Study instrument, the EPDS:}

Antenatal depression was measured using the EPDS, developed by Cox et. al (1987) validated 
for detecting depression in both antepartum and postpartum $[9,1011]$. It is the most commonly used screening tool for antenatal depression by researchers across the globe $[12,13]$. It is a brief screening tool for symptoms of depression during pregnancy, containing 10 specific questions with four likart scale response options (most of the time, some times, not often and never), targeting stress indicators occurring within the previous week in the pregnant women. It is a simple and user friendly tool, with a sensitivity and specificity of $86 \%$ and $76 \%$ respectively. Scores are recorded as $0,1,2,3$ or $3,2,1,0$ according to symptom severity. The English version of EPDS was used, and respondents who scored 12 and above were considered as likely depressives.

\section{Data analysis:}

Data obtained were fed into the statistical package for social sciences SPSS, version 23.0 and all relevant descriptive statistical variables were computed using student t-test and chi-squared test, which were also used to determine association between means of continuous variables and categorical variables respectively. Linear multiple regression analysis was used to determine the predictors of antenatal depression from a set of significant associations at bivariate analysis $(\mathrm{p}<0.05)$.

\section{Results:}

Out of 920 pregnant women who registered for antenatal care during the period of the study, 500 consented to the study. Of the 500, 158 (31.6\%) had EPDS score of 12 and above giving a prevalence rate of $31.6 \%$ for ante natal depression.

Socio-demographic characteristics of

Table 1: describes the characteristics of the study population with their risk of depression as assessed by EPDS score of 12 and above.

\begin{tabular}{|c|c|c|c|c|}
\hline Variable & $\begin{array}{l}\text { Frequency } \\
(\%)\end{array}$ & $\begin{array}{l}\text { Risk of } \\
\text { depression }\end{array}$ & $\begin{array}{l}\text { Risk of } \\
\text { depression }\end{array}$ & P value \\
\hline Age group & $\mathrm{N}=500$ & $\begin{array}{l}\text { Depressed } \\
\mathrm{n}=158\end{array}$ & $\begin{array}{l}\text { Not depressed } \\
n=342\end{array}$ & $\mathrm{P}=0.107$ \\
\hline$\leq 19$ & $3(0.6 \%)$ & $0(0 \%)$ & $3(0.9 \%)$ & \\
\hline $20-29$ & $162(32.4 \%)$ & $41(25.9 \%)$ & $121(35.9 \%)$ & \\
\hline $30-39$ & $240(48.0 \%)$ & $82(51.9 \%)$ & $158(46.2 \%)$ & \\
\hline $40+$ & $95(19.0 \%)$ & $35(22.2 \%)$ & $60(17.5)$ & \\
\hline Level of education & & & & $\mathrm{P}=0.404$ \\
\hline Primary & $10(2.0 \%)$ & $5(3.2 \%)$ & $5(1.5 \%)$ & \\
\hline secondary & $99(19.8 \%)$ & $33(20.0 \%)$ & $66(19.3 \%)$ & \\
\hline Tertiary & $391(78.2 \%)$ & $120(75.9 \%)$ & $271(79.2 \%)$ & \\
\hline Marital status & & & & $\begin{array}{l}\mathrm{P}=0.002, \mathrm{OR}: 0.532, \\
95 \% \mathrm{CL}=0.216- \\
1.311\end{array}$ \\
\hline Cohabiting & $5(1.0 \%)$ & $5(3.2 \%)$ & $0(0.0 \%)$ & OR: 1975.60 \\
\hline Married & $475(95 \%)$ & $144(91.0 \%)$ & $331(96.8 \%)$ & \\
\hline Single & $20(4.0 \%)$ & $9(5.7 \%)$ & $11(3.2 \%)$ & \\
\hline Employment status & & & & $\mathrm{P}=0.119$ \\
\hline Employed & $155(31.0 \%)$ & $41(25.9 \%)$ & $114(33.3 \%)$ & \\
\hline Unemployed & $345(69.0 \%)$ & $117(74.1 \%)$ & $228(68.4 \%)$ & \\
\hline
\end{tabular}


The mean age of the respondents was $34.12 \pm 7.8$ years, with the 30-39 years' age group forming $48 \%$ of the respondents. There was no significant association between respondents' age and depression ( $\mathrm{p}=0.107)$. Majority of the respondents, $78.2 \%$ had tertiary education. The demographic variables of level of education $(\mathrm{p}=0.404)$ and employment status $(p=0.119)$ did not show any significant association with depression on bivariate analysis $p=0.05$. About $95 \%$ of respondents were married, the $1 \%$ that cohabited with their spouses all turned out depressed $\mathrm{p}=0.002$, OR:1974.684.

Social support and social history of respondents.
Table 2 describes the respondents' support system and social history with depression. Spouses employment $(p=0.16)$ and family support $(p=0.146)$ did not show any significant association with depression. Smoking or using any illicit drugs $(p=0.236)$ and alcohol use $(p=0.178)$, did not show strong association on bivariate analysis. Support from spouse $(\mathrm{p}=0.013)$, fight with spouse $(p=0.013)$, and threat to life $(p=0.007)$ showed strong association but when put on logistic regression, support from spouse showed a weak association. The social variables of fight with spouse and threat to life turned out as strong predictors of antenatal depression. [Fight with spouse (OR:2.655, 95\%CL=i.231-5.723) and threat to life (OR:3.432, 95\%CL=1.374-8.572)].

Table 2: Respondents social history and social support with depression.

\begin{tabular}{|l|l|l|l|l|}
\hline Variable & $\begin{array}{l}\text { Frequency } \\
(\%)\end{array}$ & Risk of depression & Risk of depression & p-value \\
\hline & $\mathrm{N}=500$ & $\begin{array}{l}\text { Depressed } \\
\mathrm{n}=158\end{array}$ & $\begin{array}{l}\text { Not Depressed } \\
\mathrm{n}=342\end{array}$ & \\
\hline Spouse employment & & & & $\mathrm{P}=0.164$ \\
\hline Unemployed & $41(8.2 \%)$ & $17(10.8 \%)$ & $24(7.0 \%)$ & \\
\hline Employed & $459(91.8 \%)$ & $141(89.2 \%)$ & $318(93.6 \%)$ & \\
\hline Support from spouse & & & & $\mathrm{P}=0.013 \mathrm{OR}=0.407$ \\
\hline No & $35(7.0 \%)$ & $18(11.4 \%)$ & $17(5.0 \%)$ & $95 \% \mathrm{CL}=0.204-0.813$ \\
\hline Yes & $465(93.0 \%)$ & $140(88.6 \%)$ & $325(95.5 \%)$ & \\
\hline Family support & & & & $\mathrm{P}=0.146$ \\
\hline No & $219(43.8 \%)$ & $77(48.7 \%)$ & $142(41.5 \%)$ & \\
\hline Yes & $281(56.2 \%)$ & $81(51.3 \%)$ & $200(58.5 \%)$ & $\mathrm{P}=0.236$ \\
\hline $\begin{array}{l}\text { Smoking or illicit } \\
\text { drug use }\end{array}$ & & & & \\
\hline No & $497(99.4 \%)$ & $156(98.7 \%)$ & $341(99.7 \%)$ & \\
\hline Yes & $3(0.6 \%)$ & $2(1.3 \%)$ & $1(0.3 \%)$ & $\mathrm{P}=0.178$ \\
\hline Alcohol use & & & & \\
\hline No & $467(93.4 \%)$ & $144(91.1 \%)$ & $323(94.4 \%)$ & \\
\hline Yes & $33(6.6 \%)$ & $14(8.9 \%)$ & $19(5.6 \%)$ & $\mathrm{P}=0.013 \mathrm{OR}=2.655$ \\
\hline Fight with spouse & & & & $95 \% \mathrm{CL}=1.231-5.723$ \\
\hline No & $472(94.4 \%)$ & $143(90.5 \%)$ & $329(96.2 \%)$ & \\
\hline Yes & $28(5.6 \%)$ & $15(9.5 \%)$ & $13(3.8 \%)$ & \\
\hline $\begin{array}{l}\text { Threat to life or } \\
\text { pregnancy }\end{array}$ & & & & \\
\hline No & $480(96.0 \%)$ & $146(92.4 \%)$ & $334(97.7 \%)$ & \\
\hline Yes & $20(4.0 \%)$ & $12(7.6 \%)$ & $(2.3 \%)$ & \\
\hline
\end{tabular}




\section{Obstetrics variables with depression.}

Table 3 describes maternal obstetrics history with depression. About $61.4 \%$ of respondents were in the $3^{\text {rd }}$ trimester, and $72.8 \%$ of the pregnancies were planned. Gestational age $(\mathrm{p}=0.800)$, planned pregnancy $(\mathrm{p}=0.171)$, parity $(\mathrm{p}=0.248)$, family size $(\mathrm{p}=0.906)$, previous caesarean section $(\mathrm{p}=0.690)$ and mothers' health challenges $(\mathrm{p}=0.091)$ did not show any significant association with depression.
History of number of pregnancies lost/still birth $(\mathrm{p}=0.001)$, history of child death $(\mathrm{p}=0,002)$, and health challenges from children $(\mathrm{p}=0.012)$ all showed very strong association with depression. On logistic regression, still birth (OR: 1.11, $95 \% \mathrm{CL}=0.885-1.389$ ), child death (OR: 1.907, $95 \% \mathrm{CL}=1.232-3.953)$ and child health challenges (OR: $2.977,95 \% \mathrm{CL}=1.276-6.944)$ became very strong predictors to antenatal depression.

Table 3 showing obstetrics and maternal history with depression.

\begin{tabular}{|l|l|l|l|l|}
\hline Variables & $\begin{array}{l}\text { Frequency } \\
(\%)\end{array}$ & Risk of depression & Risk of depression & p-values \\
\hline & $\mathrm{N}=500$ & Depressed=158 & Not depressed=342 & \\
\hline $\begin{array}{l}\text { Gestational age } \\
\text { (weeks) }\end{array}$ & & & & $\mathrm{P}=0.800$ \\
\hline$\leq 13$ & $41(8.2 \%)$ & $13(8.2 \%)$ & $28(8.2 \%)$ & \\
\hline $14-26$ & $162(32.4 \%)$ & $48(30.34)$ & $114(33.3 \%)$ & \\
\hline$\geq 27$ & $297(59.4 \%)$ & $97(61.4 \%)$ & $200(58.5 \%)$ & \\
\hline Planned pregnancy & & & & $\mathrm{P}=0.171$ \\
\hline No & $116(23.2 \%)$ & $43(27.2 \%)$ & $73(21.3 \%)$ & \\
\hline Yes & $384(76.8 \%)$ & $115(72.8 \%)$ & $269(78.7 \%)$ & \\
\hline Parity & & & & $\mathrm{P}=0.248$ \\
\hline 0 & $190(38.0 \%)$ & $58(36.7 \%)$ & $132(38.6 \%)$ & \\
\hline 1 & $160(32.0 \%)$ & $45(28.5 \%)$ & $115(33.6 \%)$ & \\
\hline$\geq 2$ & $150(30.0 \%)$ & $55(34.8 \%)$ & $95(27.8 \%)$ & \\
\hline $\begin{array}{l}\text { No of pregnancies lost } \\
\text { (still birth) }\end{array}$ & & & & $\mathrm{P}=0.001, \mathrm{OR}: 1.11$, \\
\hline 0 & $347(69.4 \%)$ & $95(60.1 \%)$ & $257(73.7 \%)$ & \\
\hline 1 & $105(21.0 \%)$ & $50(31.6 \%)$ & $55(16.1 \%)$ & \\
\hline$\geq 2$ & $48(9.6 \%)$ & $13(8.2 \%)$ & $35(10.2 \%)$ & \\
\hline $\begin{array}{l}\text { Number of children } \\
\text { (family size) }\end{array}$ & & & & $\mathrm{P}=0.906$ \\
\hline 0 & $208(41.6 \%)$ & $66(41.8 \%)$ & $142(41.5 \%)$ & \\
\hline 1 & $163(32.6 \%)$ & $45(28.5 \%)$ & $118(34.5 \%)$ & \\
\hline $2-4$ & $127(25.4 \%)$ & $47(29.7 \%)$ & $80(23.4 \%)$ & \\
\hline$\geq 5$ & $2(.4 \%)$ & $0(0.0 \%)$ & $2(0.6 \%)$ & \\
\hline $\begin{array}{l}\text { No of caesarean } \\
\text { sections. }\end{array}$ & & & & \\
\hline 0 & $366(73.2 \%)$ & $118(74.7 \%)$ & $248(72.5 \%)$ & \\
\hline 1 & $89(17.8 \%)$ & $24(15.2 \%)$ & $64(19.0 \%)$ & \\
\hline 2 & $38(7.6 \%)$ & $13(8.2 \%)$ & $25(7.3 \%)$ & \\
\hline 3 & $7(1.4 \%)$ & $3(1.9 \%)$ & $4(1.2 \%)$ & \\
\hline
\end{tabular}




\begin{tabular}{|l|l|l|l|l|}
\hline $\begin{array}{l}\text { Death of } \\
\text { child/children }\end{array}$ & & & & $\begin{array}{l}\mathrm{P}=0.002, \mathrm{OR}: 1.907, \\
95 \% \mathrm{CL}=1.232-3.953 .\end{array}$ \\
\hline 0 & $443(88.6 \%)$ & $133(84.2 \%)$ & $310(90.0 \%)$ & \\
\hline 1 & $47(9.4 \%)$ & $17(10.8 \%)$ & $30(8.8 \%)$ & \\
\hline$\geq 2$ & $10(2.0 \%)$ & $8(5.1 \%)$ & $2(0.6 \%)$ & \\
\hline $\begin{array}{l}\text { Child health } \\
\text { challenges }\end{array}$ & & & & $\begin{array}{l}\mathrm{P}=0.012, \mathrm{OR}: 2.977 \\
95 \% \mathrm{CL}=1.276-6.944\end{array}$ \\
\hline No & $477(95.4 \%)$ & $145(91.8 \%)$ & $332(97.1 \%)$ & \\
\hline Yes & $23(4.6 \%)$ & $13(8.2 \%)$ & $10(2.9 \%)$ & \\
\hline $\begin{array}{l}\text { Personal health } \\
\text { challenges }\end{array}$ & & & & $\mathrm{P}=0.091$ \\
\hline $\begin{array}{l}\text { No } \\
\text { Yes }\end{array}$ & $\begin{array}{l}456(91.2 \%) \\
44(8.8 \%)\end{array}$ & $\begin{array}{l}139(88.0 \%) \\
19(12.0 \%)\end{array}$ & $\begin{array}{l}317(92.7 \%) \\
25(7.3 \%)\end{array}$ & \\
\hline
\end{tabular}

\section{Discussion:}

In this study, we have measured the prevalence of antenatal depression among women attending antenatal care at RSUTH and its association with certain risk factors such as socio-demographic characteristics, social support and financial support and obstetrics history. The prevalence of depression during pregnancy was $31.6 \%$ using an EPDS cut off score of $\geq 12$ among the respondents. This may appear high compared to the few studies done in the country, but considering the peculiarity of the setting, it is not surprising. This result is in keeping with the findings of B. Sheeba et. al [14], who reported $37.8 \%$. In a similar study in Bangalure, T, J Rochat et. al (15) recorded a prevalence of $45 \%$ in South Africa. It also falls within the range reported by Abel Fekadu Dadi et. al (2020) [3] in a systemic meta- analysis in Africa which they reported a range of $8.3 \%$ to $78 \%$.

In another study in Gundar town, Abel Fekadu et. al (2020) [16] reported a prevalence rate of $10.4 \%$ $57 \%$ in lower Asian countries and $22.7 \%$ to $38.5 \%$ amongst African countries. Other studies in the continent reported a $21 \%$ prevalence from Malawi, and $25 \%$ from Ethiopia. In Nigeria, a few studies have reported prevalence rates of $9 \%, 24.5 \%$, and $11.3 \%$ under different settings $[6,8,19]$.

In this study, the mean age of respondents was $34.12 \pm 7.8$ ranging from 17 to $50 \mathrm{yr}$, depression peaked with the 30-39yr age group, but showed no significant association $\mathrm{p}=0.107$. Seventy eight percent of the respondents had tertiary education, while only $2 \%$ had primary education. Contrary to Okechukwu T. et al 2010, level of education was not a significant risk factor in this study. Being married generally confers a good prognosis to being depressed, but in this study $95 \%$ of the respondents were married and $91 \%$ of the depressed group were married. Five of the respondents were cohabiting and all of them were depressed. Marital status showed a strong association with depression across all the groups $\mathrm{p}=0.002$. On logistic regression, married OR:0.532, cohabiting OR:198.69. Though $69 \%$ of respondents were unemployed, it did not pose as a threat to being depressed $p=0.119$.

Social variables of spouse employment $(\mathrm{p}=0.114)$, family financial support $\mathrm{p}=0.146$, smoking $\mathrm{p}=0.236$ and alcohol intake $\mathrm{p}=0.236$ showed no significant association with depression. Not receiving social and financial support from spouses during pregnancy showed a strong association with being depressed. Of the 35 respondents who had no support from their spouses, 18 turned out depressed on bivariate analysis $\mathrm{p}=0.013$, but with OR: 0.407 when 'No' was used on logistic regression. This is in keeping with the findings of Desiree Govender et. al (2020) [20], Okechukwu Thompson et. al (2016), and Benett H.A et. al (2004). Fifteen respondents out of 28 who were physically abused by their spouses had depression $\mathrm{p}=0.013,95 \% \mathrm{CL}=1.231-5.723$. 
Kaiyo-Utefe M. et.al (2020) [(21], reported an intimate partner violence OR:2.45, while Desiree Govender et. al reported violence from partner with OR:2.6, 95\%CL=1.6-4.2, $\mathrm{p}=0.001$. This study has shown a strong association between lack of spouse support, partner violence, and depression. These two risk factors invariably lead to unbearable pregnancy situations and a threat to mother and baby. In this study, 12 out of 20 respondents who indicated there was a threat to life or pregnancy, were depressed $\mathrm{p}=0.007, \mathrm{OR}: 3.432$, $95 \% \mathrm{CL}=1.374-8.572$. This was also the finding of Getinet Ayano et.al (2019) [22].

The mean gestational age in this study was $29.7 \pm$ 8.46 weeks, $\mathrm{AD}$ peaked in the $3^{\text {rd }}$ trimester showing an appropriate increase across the three trimesters without any strong association between gestational age and depression $\mathrm{p}=0.800$. Unplanned pregnancy has been reported as risk factor for $A D$ in several studies $[8,23,24]$. In this study 'planning - pregnancy' $p=0.171$, 'parity' $\mathrm{p}=0.248$, and family size $\mathrm{p}=0.906$, did not show any significant association with depression.

Adewuya A. et. al (2007) assessed depression in late pregnancy in a Nigerian facility and reported 'still birth' as a predictor to AD OR: 8.00, $95 \% \mathrm{CL}=1.70-37.57$. In this study, loosing previous pregnancies (still birth) showed a strong association on bivariate analysis $p=0.001$, however, weak but significant association was noticed on multivariate logistic regression analysis OR: 1.11. History of previous caesarean sections has been associated with AD [8,25,26], although this study did not show any strong association between previous caesarean sections and depression $\mathrm{p}=0.690$.

In this study, 10 respondents reported that at least two of children had died previously, 8 of them turned out depressed $\mathrm{p}=0.002$, OR:1.907, $95 \% \mathrm{CL}=1.232-2.953$. Another group of respondents who indicated they had children with serious health challenges showed a strong association with depression $\mathrm{p}=0.012$. OR:2.977, $95 \% \mathrm{CL}=1.276-6.944$. Death of children and child health challenges turned out as predictors to AD.

\section{Study strength and limitations:}

This study focussed on AD which had received less attention from this part of the world. The setting of this study is a teaching hospital in the cosmopolitan city of Port Harcourt Nigeria. The respondents are of middle to middle-upper class, which may explain the outcome of variables of level of education, employment status and others. The inclusion criteria excluded women with high risk pregnancies. We used EPDS with cut-off of $\geq$ 12 with high sensitivity and specificity and ease of administration. It is always important to confirm the presence of depression by using a structured clinical interview to confirm diagnoses.

\section{Conclusion and Recommendation:}

This study showed a high prevalence rate of $31.6 \%$ for antenatal depression in Port Harcourt Nigeria, which was evenly distributed through the three trimesters. Risk factors such as cohabiting with spouse, lack of financial and social support from spouse, fight with spouse, threat to life, history of still birth, previous child death and having children with health challenges were determined. Of these risk factors, fight with spouse, threat to life, child death and child health challenges turned out as predictors of antenatal depression. Obstetrics practice in this part of the world should include screening and diagnosis for antenatal depression as part of antenatal care.

\section{Consent:}

All respondents signed a written consent, and consent was obtained from all relevant authorities.

\section{Author contributions:}

Enyidah N S designed the study and wrote the draft preparation. Nonye-Enyidah E.I. supervised data collection and analysis and edited the script.

\section{Funding:}

No funding sources.

\section{Acknowledgments:}

We would like to express our gratitude to all the women who consented to the study, all the doctors who assisted in data collection and staff of the antenatal clinic of the hospital. 


\section{References:}

1. Sadock BJ, Sadock VA, Ruitz P. (2019) Synopsis of Psychiatry and Behavioural Sciences/Clinical psychiatry. In Kaplan and Sadock (Eds). Mood Disorder. $11^{\text {th }}$ edition. Wolters Kluwer, 2019; 347- 386.

2. World Health Organization Guidelines approved by the guidelines review committee, mhGAP intervention Guide for mental, Neurological and substance use Disorders in Non-specialised Health setting: Mental Health Gap Action Programme (mhGAP), Geneva; WHO; 2010.

3. Abel Fekadu Dadi, Haileab Fekadu Wold, Adhanom G. Baraki and Temesgen Y. Akalu. Epidemiology of antenatal depression in Africa; A systematic review of meta-analysis. BMC Pregnancy and childbirth. 2020; 20: 251.https//doi.org/10.1186/s12884-02002929-5.

4. Bennett HA, Einorson A., Toddio A., Koreng G., Einorson TR. Prevalence of depression during pregnancy: Systemic review. Obst. Gynecol. 2004; 103 (4), 690-709.

5. Bereket Duko, Getinet Ayano and A. Bedaso. Depression among pregnant women and associated factors in Hawassa city, Ethiopia; an institution based cross-sectional study. Reproductive Health; 2019; 16: 25.https//doi.org/10.1186/s12978-019-0685-x

6. Adewuya AO., Ola BA., Alibo OO., Dada AO.,Fasedo OO. Prevalence and correlates of depression in late pregnancy among Nigerian women. Depression Anxiety. 2007; 24: (1), 1521.

7. Abel Fekadu Dadi, Emma R. Miller, Richard Woodmen, Telake Azali Bisetegn and Lillian Miranri. Antenatal depression and its potential causal mechanisms among pregnant mothers in Gundar town; application of structural equation model. BMC pregnancy and Childbirth, 2020; 20: article 168. https://doi.org/10.1186/s12884-020-02859-2.

8. Okechukwu Thompson and Ike O. Ajayi. Prevalence of antenatal depression and associated risk factors among pregnant among pregnant women attending Antenatal clinic in
Abeokuta North local government Area Nigeria. Depression, Research and Treatment, vol. 2016, article ID 4518979, 15 pages.

9. Cox JL., Holden JM., Sagovsky R. Detection of postnatal Depression; development of the 10-item Edinburgh Postnatal depression scale. Br. J. psychiatry. 1987; 150: 782-786.

10. Hanlon C., Medhin G. Alem A., Araya M., Abdulahi A., Hughes M. et. al. Detecting perinatal common mental disorders in Ethiopia; validation of the self-reporting questionnaire and Edinburgh postnatal depression scale. J Affect. Disorder, 2008; 108 (3): 251-262

11. Murry L., Carothers AD. The validation of EPDS in a community sample. Br.J. Psy. 1990; 157: 288-290.

12. Chowe-Sundani G., Chipps J. A systematic review of screening instruments for depression for use in antenatal services in low resources settings. BMC psychiatry; 2017: 17 (1).

13. Su KP., Chiu TH., Huana CL. Et. al. Cut off points for different trimester? The use of Edinburgh postnatal depression scale and Beck depression inventory to screen for depression in pregnant Taiwanese women. Gen. Hospital psychiatry. 2007; 29(5):436-441.

14. B. Sheeba, Anita Nath, Candra S. Matgud, Murali Krisha, et.al. Prenatal depression and it's associated risk factors among pregnant women in Bangalore. A hospital based prevalence study. Front. Public Health, 03, may 2019.

15. T.J. Rochat, M. Tomlinson, M.L Newell and A. Stein. Detection of antenatal depression in rural Hiv-affected population with short and ultra-short version of EPDS. Archives of women's mental health. 2013; Vol. 16, N0 5, pp 40-410.

16. Amiel Castro RT, Pinard Anderman C, Glover V, O'Connor TG, Ehlert U, Kammerer M. associated symptoms of depression: Patterns of change during pregnancy. Arch Women's Ment Health. 2017; 20(1): 123-128.

17. R.C. Stewart, E. Umar, B Tumenson, and F Creed. A cross-sectional study of Antanatal Depression and associated factors in Malawi. 
Archives of women's Mental health, 2014;17(2): 145-154.

18. A. Broatu, and D Haile. Prevalence of antenatal depression and associated factors among pregnant women in Addis Ababa Ethiopia; A cross sectional study. Reproductive Health, 2015; 12 (99).https://doi.org/10.1186/s12978-0150092-x

19. Mashudat A, Bello Mojeed. Prevalence and correlates of depression among women attending antenatal clinic in Lagos. Faculty of psychiatry, National Postgraduate Medical College of Nigeria. 2014.

20. Desiree Govender, Salichni Naidro and Myra Taylor. Antenatal and Postnatal Depression; Prevalence and associated risk factors among Adolescents in KwaZulu-Watel, South Africa. Depression and treatment, volume 2020, article ID; 5364521.

21. M.Kaiyo-Utete, JM. Dambi. Antenatal depression; An examination of prevalence and it's associated factors among pregnant women attending Harare polyclinics. BMC, pregnancy and Chilbirth, 2020; 20: 197.

22. Getrinet Ayano, Getachew Tesfaw and Shegaye Shumet. Prevalence and determinants of antenatal depression in Ethiopia: A systematic review and meta-analysis. Plos Global Public Health, 2019/doi.59/10.137/ID0211764.

23. C. A. Lancaster, KJ Gold, HA Flynn, H Yoo, SM Marcus and MM Davis. Risk factors for depressive symptoms during pregnancy; A systematic review: American journal of Obstetrics and Gynaecology, 2010; vol 202, N01, pp 5-14.

24. B. Leigh and J Milgram. Risk factors for antenatal depression, postnatal depression and parenting stress. BMC psychiatry. 2008; vol. 8, article 24.

25. S. Ajinkya, PJadjav and N Srivastava. Depression during pregnancy; prevalence and Obstetric risk factors among pregnant women attending a tertiary care in Navi Mumbai. Industrial psychiatry journal.2013; Vol. 22, N01, 37-40. 